\title{
ERRATUM
}

\section{Erratum to: Deep Phenotyping of Systemic Arterial Hemodynamics in HFpEF (Part 1): Physiologic and Technical Considerations}

Julio A. Chirinos ${ }^{1,2}$

Published online: 21 April 2017

(C) Springer Science+Business Media New York 2017

Erratum to: $\mathbf{J}$ of Cardiovasc Trans Res

DOI: $10.1007 / \mathrm{s} 12265-017-9735-3$

Please note that in the penultimate sentence of the "Other Approaches" section of this article as originally published, "diastole" and mid-systole" were incorrectly given as ““'diastoles" and "mid-systoles", respectively. The original article has been corrected.

The online version of the original article can be found at http://dx.doi.org/ 10.1007/s12265-017-9735-3

$\triangle$ Julio A. Chirinos

Julio.Chirinos@uphs.upenn.edu

1 University of Pennsylvania Perelman School of Medicine and Hospital of the University of Pennsylvania, Philadelphia, PA, USA

2 Perelman Center for Advanced Medicine, South Tower, Rm. 11-138, 3400 Civic Center Blvd, Philadelphia, PA 19104, USA 